\title{
The NuRD chromatin-remodeling complex enzyme CHD4 prevents hypoxia-induced endothelial Ripk3 transcription and murine embryonic vascular rupture
}

\author{
Sarah Colijn ${ }^{1,2} \cdot$ Siqi Gao ${ }^{1,2} \cdot$ Kyle G. Ingram ${ }^{1,2,4} \cdot$ Matthew Menendez $^{1} \cdot$ Vijay Muthukumar $^{1,5} \cdot$ Robert Silasi-Mansat $^{1}$. \\ Joanna J. Chmielewska, ${ }^{1,6}$ Myron Hinsdale ${ }^{3}$. Florea Lupu ${ }^{1,2} \cdot$ Courtney T. Griffin (i) $^{1,2}$
}

Received: 15 September 2017 / Revised: 10 May 2019 / Accepted: 11 June 2019 / Published online: 24 June 2019

(c) The Author(s), under exclusive licence to ADMC Associazione Differenziamento e Morte Cellulare 2019

\begin{abstract}
Physiological hypoxia can trigger transcriptional events that influence many developmental processes during mammalian embryogenesis. One way that hypoxia affects transcription is by engaging chromatin-remodeling complexes. We now report that chromodomain helicase DNA binding protein 4 (CHD4), an enzyme belonging to the nucleosome remodeling and deacetylase (NuRD) chromatin-remodeling complex, is required for transcriptional repression of the receptor-interacting protein kinase 3 (Ripk3) - a critical executor of the necroptosis cell death program - in hypoxic murine embryonic endothelial cells. Genetic deletion of Chd4 in murine embryonic endothelial cells in vivo results in upregulation of Ripk3 transcripts and protein prior to vascular rupture and lethality at midgestation, and concomitant deletion of Ripk3 partially rescues these phenotypes. In addition, CHD4 binds to and prevents acetylation of the Ripk3 promoter in cultured endothelial cells grown under hypoxic conditions to prevent excessive Ripk3 transcription. These data demonstrate that excessive RIPK3 is detrimental to embryonic vascular integrity and indicate that CHD4 suppresses Ripk 3 transcription when the embryonic environment is particularly hypoxic prior to the establishment of fetal-placental circulation at midgestation. Altogether, this research provides new insights into regulators of Ripk3 transcription and encourages future studies into the mechanism by which excessive RIPK3 damages embryonic blood vessels.
\end{abstract}

These authors contributed equally: Sarah Colijn, Siqi Gao, Kyle G. Ingram

Edited by J. Silke

Supplementary information The online version of this article (https:// doi.org/10.1038/s41418-019-0376-8) contains supplementary material, which is available to authorized users.

Courtney T. Griffin

courtney-griffin@omrf.org

1 Cardiovascular Biology Research Program, Oklahoma Medical Research Foundation, Oklahoma City, OK 73104, USA

2 Department of Cell Biology, University of Oklahoma Health Sciences Center, Oklahoma City, OK 73190, USA

3 Department of Physiological Sciences, Oklahoma State University, Stillwater, OK 74078, USA

4 Present address: Stowers Institute for Medical Research, Kansas City, MO 64110, USA

5 Present address: The Jackson Laboratory, Bar Harbor, ME 04609, USA

6 Present address: Centre of New Technologies, University of Warsaw, 02-097 Warsaw, Poland

\section{Introduction}

Hypoxia, the condition of low oxygen availability, influences a variety of physiological and pathological processes. The mammalian embryonic environment is particularly hypoxic (less than $2 \%$ oxygen) before blood circulation to the placenta is established at midgestation, since the placenta is a critical site of oxygen exchange between maternal and embryonic blood [1]. This hypoxia is essential for the physiological development of the embryo and is involved in trophoblast differentiation, placental vascularization, heart development, neural crest cell migration, and chondrogenesis [1].

Many of the cellular changes induced by hypoxia result from transcriptional cues triggered by low oxygen availability. Hypoxia influences transcription by stabilizing hypoxia-inducible factor (HIF) transcription factors and by inducing epigenetic modifications to DNA and to chromatin-associated proteins [2, 3]. Such epigenetic modifications include changes to DNA methylation, the removal or addition of methyl or acetyl groups to histones, 
and alterations in ATP-dependent chromatin-remodeling complex activities. These epigenetic changes directly impact gene transcription by altering the accessibility of gene regulatory regions to a variety of positive and negative transcriptional regulatory proteins. Therefore, the effects of hypoxia on transcription are widespread, and genes that are transcriptionally affected by hypoxia are not necessarily predictable by the presence or absence of an HIF-binding site in their regulatory regions.

Our lab previously reported that the ATP-dependent chromatin-remodeling complex called the nucleosome remodeling and deacetylase (NuRD) complex and its ATPase chromodomain helicase DNA binding protein 4 (CHD4) are essential for embryonic development [4]. When CHD4 is deleted from embryonic endothelial cells using the Tie2-Cre transgene, embryos die from abdominal vascular rupture at embryonic day 11.5 (E11.5) [4]. The embryonic days prior to midgestation are characterized by especially low levels of oxygen until the fetal-placental circulation is established around E10.0 [5]. This led us to question whether CHD4 and the NuRD chromatin-remodeling complex help regulate the embryonic response to hypoxia to maintain vascular integrity at midgestation.

Mounting evidence in the literature indicates that another protein, receptor-interacting protein kinase 3 (RIPK3), regulates vascular integrity at the same embryonic stage as CHD4 [6]. RIPK3 is an important component of necroptotic cell death complexes, and its downstream effector-the phosphorylated mixed lineage kinase domain-like (MLKL) protein-facilitates necroptosis by permeabilizing the plasma membrane [7]. Necroptosis, like apoptosis, is a programmed form of cell death that can be triggered by activation of cell surface death receptors (i.e., tumor necrosis factor receptors) or pathogen recognition receptors (i.e., Toll-like receptors) and the subsequent assembly of cytoplasmic death complexes [8]. During murine embryonic development, RIPK3 mediates lethality at midgestation if not suppressed by components of the extrinsic apoptosis pathway [6]. For example, global deletion of the apoptosis pathway components Caspase 8 (Casp8), FADD (Fadd), or c-FLIP (Cflar) results in embryonic lethality preceded by cardiovascular abnormalities, including aneurysms or hemorrhaging in the abdominal region, which is similar in timing and location to the lethal hemorrhaging seen in $\mathrm{Chd}^{\mathrm{flf} / \mathrm{Fie}}$;-Cre ${ }^{+}$mutants [4, 9-11]. These vascularassociated midgestation lethalities seen in apoptosis pathway mutants can be rescued by simultaneous genetic deletion of Ripk3 [12, 13], thereby signifying that there is a tenuous balance between cell survival, apoptosis, and RIPK3 expression levels at this time point.

We now report that CHD4 transcriptionally suppresses RIPK3 in hypoxic endothelial cells, likely through deacetylation of the Ripk3 promoter region, thereby preventing vascular rupture at midgestation. These results provide novel information about Ripk 3 transcriptional regulation in endothelial cells and raise new questions about the contribution of hypoxia-driven Ripk3 transcription to postnatal ischemic vascular pathologies.

\section{Results}

\section{Chd $4^{\text {fl/fl }} ;$ Tie2-Cre $^{+}$embryonic endothelial cells appear necrotic one day prior to vascular rupture}

We previously reported that $\mathrm{Chd} 4^{f / f}$; $\mathrm{Tie} 2-\mathrm{Cr} e^{+}$embryos consistently die from vascular rupture and abdominal hemorrhage at E11.5 [4]. Since the Tie2-Cre transgene is active in both endothelial and hematopoietic cells [14], we crossed Chd4-flox mice onto either the Cdh5(PAC)$\mathrm{Cre}^{E R T 2}$ or Vav-iCre transgenic lines to determine if the abdominal rupture phenotype seen in $\mathrm{Chd} 4^{\text {fl/f }} ; \mathrm{Tie}^{2}-\mathrm{Cre}^{+}$ embryos was a result of $C h d 4$ deletion in endothelial cells or hematopoietic cells. The $C d h 5(P A C)-C r e^{E R T 2}$ line, which is driven by the promoter of the gene encoding VECadherin [15], is likely inducible in both endothelial and hematopoietic cells in early embryogenesis, particularly when tamoxifen is administered prior to E11.5 $[16,17]$. So we were unsurprised to find that $C h d 4^{f / f} ; C d h 5(P A C)$ $C r e^{E R T 2}$ embryos displayed a similar timing and vascular rupture phenotype as $\mathrm{Chd} 4^{f l / f}$; $\mathrm{Tie} 2-\mathrm{Cre}^{+}$embryos (Supplementary Fig. S1A-H). However, Vav-iCre is expressed almost exclusively in hematopoietic cells outside of the testes [16, 18-20], and Chd4 $4^{f / f} ; \mathrm{Vav}-i \mathrm{Cre}^{+}$embryos displayed no overt phenotype at E12.5 (Supplementary Fig. S1I, J). Together these data indicate that Chd4 deletion in endothelial cells is the primary cause of the

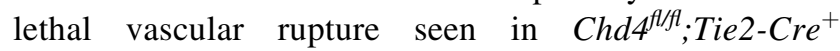
embryos by E11.5.

We next sought to evaluate endothelial cell morphology preceding vascular rupture by examining E10.5 control and $\mathrm{Chd}^{\mathrm{flfl}} ; \mathrm{Tie} \mathrm{C}-\mathrm{Cr} \mathrm{e}^{+}$littermate embryos by electron microscopy. In semithin sections, we observed rounded and swollen endothelial cells lining the lumens of $\mathrm{Chd} 4^{f / f}$;Tie2$\mathrm{Cre}^{+}$vessels (Fig. 1a, b). Transmission electron microscopy (TEM) further revealed plasma membrane breakdown and mitochondrial swelling in $\mathrm{Chd} 4^{f / f} ; \mathrm{Tie}^{-}-\mathrm{Cre}^{+}$endothelial cells (Fig. 1c, d). These phenotypes are characteristics of necrotic cell death [21]. Notably, we saw no signs of cell shrinkage, membrane blebbing, apoptotic bodies, nuclear fragmentation, or chromatin condensation in mutant samples, indicating $\mathrm{Chd}_{4}^{\mathrm{flf} f}$; $\mathrm{Tie} 2-\mathrm{Cr} e^{+}$endothelial cells are not apoptotic prior to vascular rupture. Likewise, we previously reported that TUNEL and active Casp3 staining were not

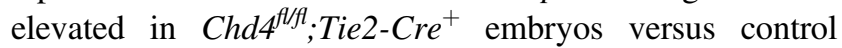
embryos at E10.5 [4]. 


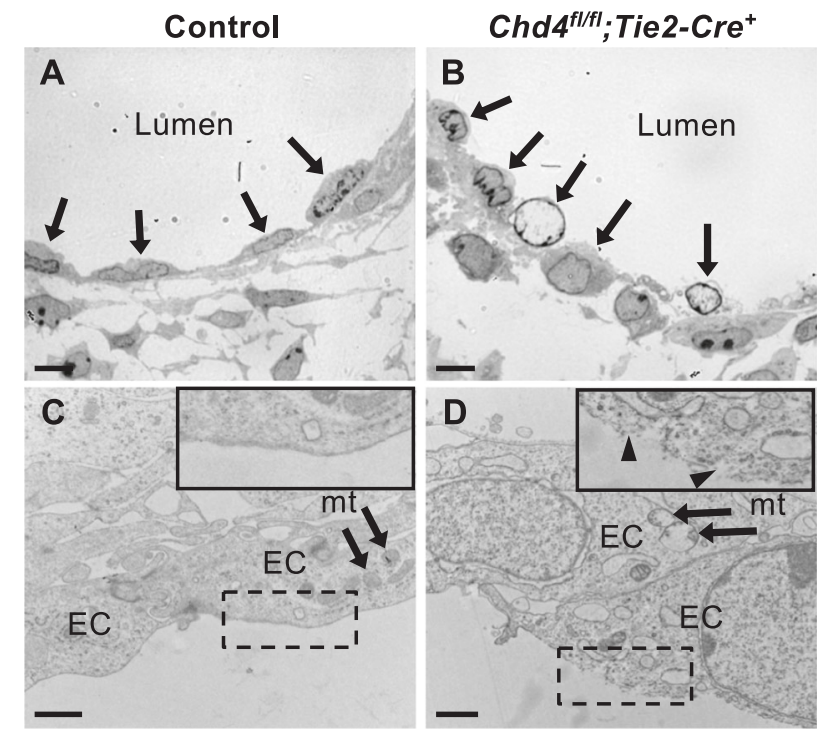

Fig. $1 \mathrm{Chd} 4^{f / f} ; \mathrm{Tie} 2-\mathrm{Cr} e^{+}$embryonic endothelial cells are necrotic prior to vascular rupture. Two sets of E10.5 littermate control and Chd $4^{\text {flfl }}$;Tie2-Cre ${ }^{+}$embryos were processed for analysis by light microscopy and transmission electron microscopy (TEM). a, b Light microscopy of semithin sections reveals swollen and round endothelial cells lining mutant vessels (b, arrows) versus flat and elongated endothelial cells in control vessels (a, arrows). c, d TEM micrographs display plasma membrane breakdown in mutant endothelial cells (ECs) (d, see arrowheads in inset) versus smooth and intact plasma membranes in control endothelial cells (c, see inset). Moreover, mitochondria (mt) are abnormally swollen in mutant endothelial cells. Scale bars: $10 \mu \mathrm{m}(\mathbf{a}, \mathbf{b}) ; 1 \mu \mathrm{m}(\mathbf{c}, \mathbf{d})$

\section{Ripk3 is upregulated in $\mathrm{Chd}^{\mathrm{f} / \mathrm{f}} ; \mathrm{Tie2}^{-\mathrm{Cre}^{+}}$ endothelial cells and contributes to vascular rupture at E11.5}

Since CHD4 frequently exerts its cellular actions through transcriptional regulation of target genes, we performed microarray analysis on six stage-matched control and six stage-matched $\mathrm{Chd} 4^{f / f}$;Tie2-Cre ${ }^{+}$E9.5 embryos to identify misregulated expression of genes that could cause the necrotic endothelial cell phenotypes observed in our mutant embryos at E10.5. Although the pool of candidate genes we recovered with significant changes in expression was small, we noted an upregulation in the necroptosis executor gene

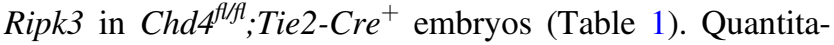
tive real-time PCR (qPCR) performed on isolated E10.5 embryonic endothelial cells confirmed that Ripk3 transcripts were upregulated in $\mathrm{Chd} 4^{\mathrm{Alfl}} ; \mathrm{Tie}^{-} \mathrm{Cre}^{+}$vasculature (Fig. 2a). Moreover, immunostaining of E10.5 embryonic sections revealed upregulated RIPK3 protein in Chd4 $4^{A / f}$; $\mathrm{Tie} 2-\mathrm{Cre}^{+}$versus control endothelial cells of cardinal veins and capillaries (Fig. 2b, c and Supplementary Fig. S2A, B). Since we observed increased Ripk3 transcripts as early as E9.5 (Table 1), we also immunostained for RIPK3 protein at E9.5 and detected elevated RIPK3 in the endocardium
Table 1 Genes misregulated in E9.5 $\mathrm{Chd} 4^{\mathrm{Alf}}$; $\mathrm{Tie} 2-\mathrm{Cre}^{+}$embryos

\begin{tabular}{lll}
\hline $\begin{array}{l}\text { Fold } \\
\text { change }^{*}\end{array}$ & Gene symbol & Description \\
\hline 3.54 & Hbb-b1 & Hemoglobin, beta adult major chain \\
1.94 & Fbxo2 & $\begin{array}{l}\text { F-box protein 2 } \\
\text { Colony stimulating factor 2 receptor, } \\
\text { beta 2, low affinity (granulocyte- } \\
\text { macrophage) }\end{array}$ \\
& Csf2rb2 & (Trim43b) Tripartite motif- \\
& containing 43B \\
1.27 & EG666747 & $\begin{array}{l}\text { Dual specificity phosphatase 2 } \\
\text { Receptor-interacting serine-threonine } \\
\text { kinase 3 }\end{array}$ \\
1.24 & Dusp2 & H2A histone family, member J \\
1.23 & Ripk3 & Solute carrier organic anion transporter \\
family, member 2b1 & Glycoprotein 9 (platelet) \\
-1.20 & H2afj & Tubulin, beta 1 class VI \\
-1.26 & Slco2b1 & Microsomal glutathione S-transferase 1 \\
-1.29 & Gp9 & Arachidonate 12-lipoxygenase \\
-1.31 & Tubb1 & Glycoprotein 5 (platelet) \\
-1.39 & Mgst1 & Myeloperoxidase \\
-1.48 & Alox12 & Triggering receptor expressed on \\
-1.57 & Gp5 & myeloid cells-like 1 \\
-1.97 & Mpo & (Pf4) Platelet factor 4 \\
-2.06 & Treml1 &
\end{tabular}

${ }^{*} P<0.001$

Six control and six Chd4fl/fl;Tie2-Cre+ E9.5 embryos were subjected to whole genome microarray analysis to detect transcript expression differences. Transcripts with a significant fold change difference $(P<$ 0.001 ; two-sample $t$ test) between control and mutant embryos are listed.

lining $\mathrm{Chd} 4^{\mathrm{flf} f}$;Tie2-Cre ${ }^{+}$embryonic hearts (Supplementary Fig. S2C, D).

To determine the relationship between the upregulated RIPK3 expression in $\mathrm{Chd}^{\mathrm{flfl}}$; $\mathrm{Tie} 2-\mathrm{Cre}^{+}$endothelial cells and the vascular rupture that occurs in these mutants at E11.5, we genetically deleted Ripk3 in Chd4/f/f $;$ Tie2-Cre $^{+}$embryos and assessed embryonic phenotypes at E12.5 (Fig. 2d-g). Deletion of a single Ripk 3 allele rescued vascular rupture in the abdominal region of 11 out of $17 \mathrm{Chd}^{\text {flfff }}$;ie2-Cre ${ }^{+}$ embryos, although these $\mathrm{Ripk}^{+-}{ }^{-} ; \mathrm{Chd} 4^{\mathrm{Alf} / \mathrm{Cie}}$;-Cre $\mathrm{Cr}^{+}$embryos displayed bleeding in brain ventricles (Fig. 2f). However, deletion of both Ripk3 alleles rescued all major hemorrhaging

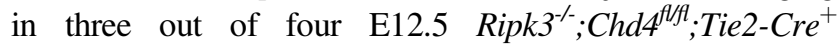
embryos (Fig. 2g), although the majority of rescued embryos did not survive past E12.5. To determine if Chd4 deletion affects Ripk3 upregulation in a cell-autonomous manner, we generated a Ripk3-flox murine model (Supplementary Fig. S3) and crossed it onto the Chd4 $4^{f / f}$;Tie2-Cre ${ }^{+}$background. $\mathrm{Ripk}^{\mathrm{fl} /+} ; \mathrm{Chd} 4^{f / f} ; \mathrm{Tie} 2-\mathrm{Cr} \mathrm{e}^{+}$embryos also showed a partial rescue of lethality over $\mathrm{Chd4^{f/f }} ; \mathrm{Tie2}^{-\mathrm{Cr} e^{+}}$embryos at E12.5 (Fig. 2i, j), with a similar brain bleeding phenotype to that 


\section{A qPCR: Isolated embryonic ECs}
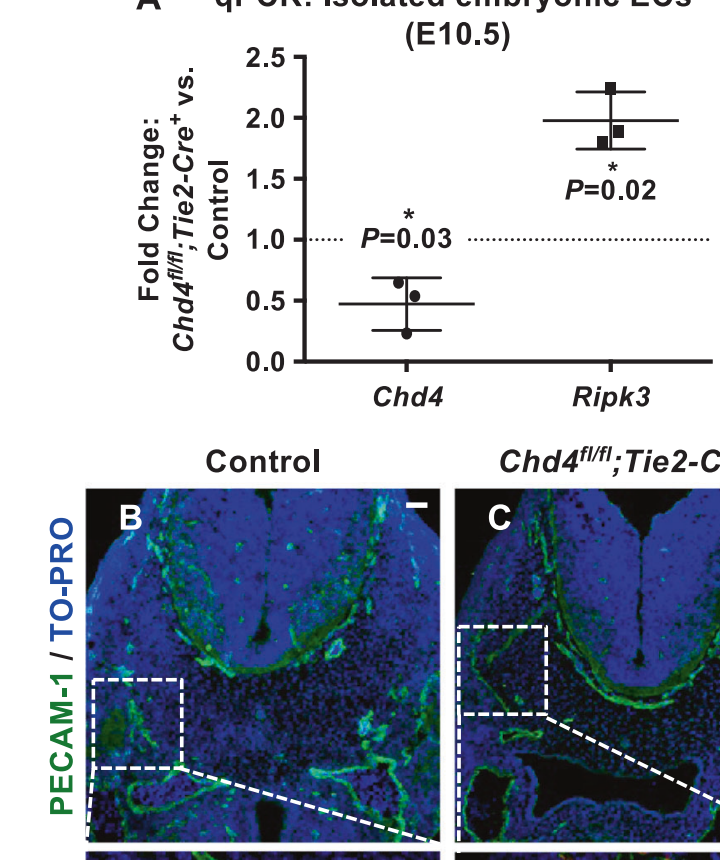

\section{$\mathrm{Chd}^{\text {fl/fl }}$;Tie2-Cre ${ }^{+}$}
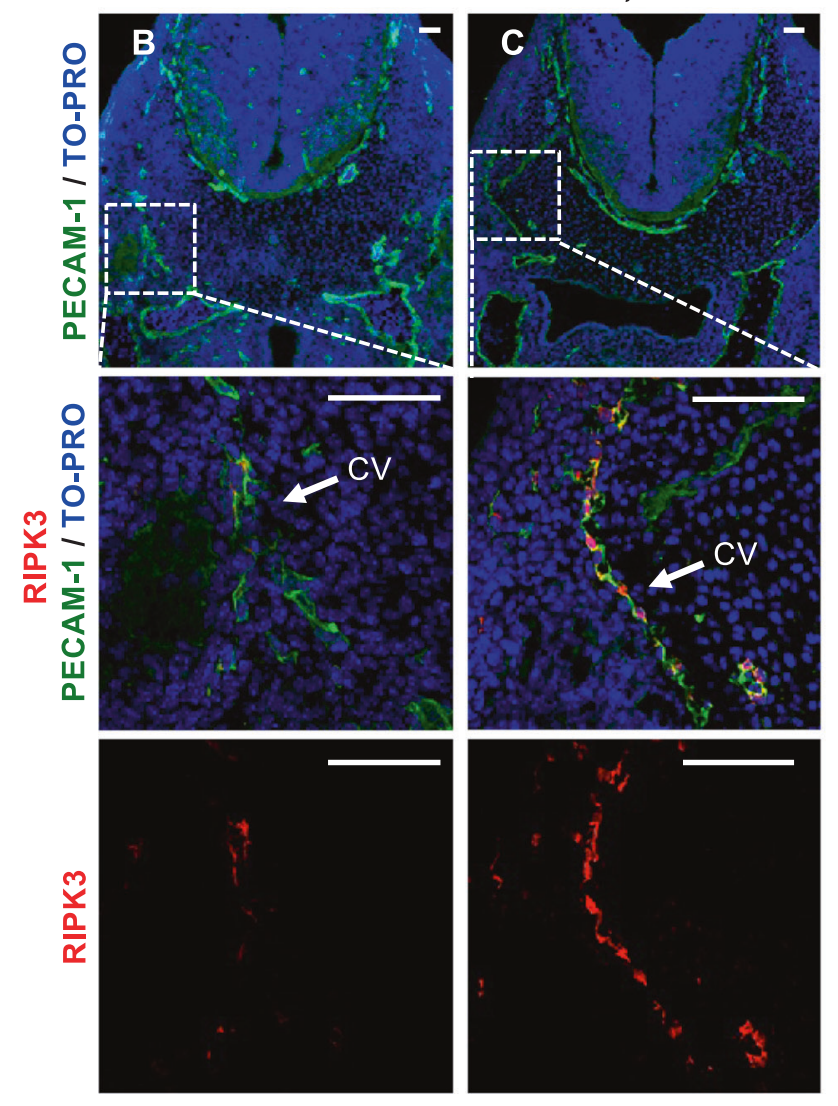

E10.5

seen in Ripk $^{+/-}$;Chd4 $4^{\text {flff }}$;Tie2-Cre ${ }^{+}$embryos (Fig. 2f, j). However, the frequency of rescue in $\operatorname{Ripk}^{f l /+}$;Chd4 ${ }^{f l / f}$;Tie2$\mathrm{Cr}^{+}$embryos was diminished compared to the rescue rate seen in Ripk3 ${ }^{+/-}$;Chd4 ${ }^{f / f l}$;Tie2-Cre ${ }^{+}$embryos. We suspect that this discrepancy is a result of the different predominant background strains on which the Ripk3-flox versus Ripk3 global knockout rescue experiments were performed. While the abdominal rupture phenotype in Chd4 ${ }^{f / f t}$;Tie2-Cre ${ }^{+}$ embryos was fully penetrant at E11.5 regardless of background, the frequency of rescue after Ripk3 deletion decreased when the background shifted from an outbred CD1 background to an inbred $\mathrm{C} 57 \mathrm{Bl} / 6 \mathrm{~J}$ background.
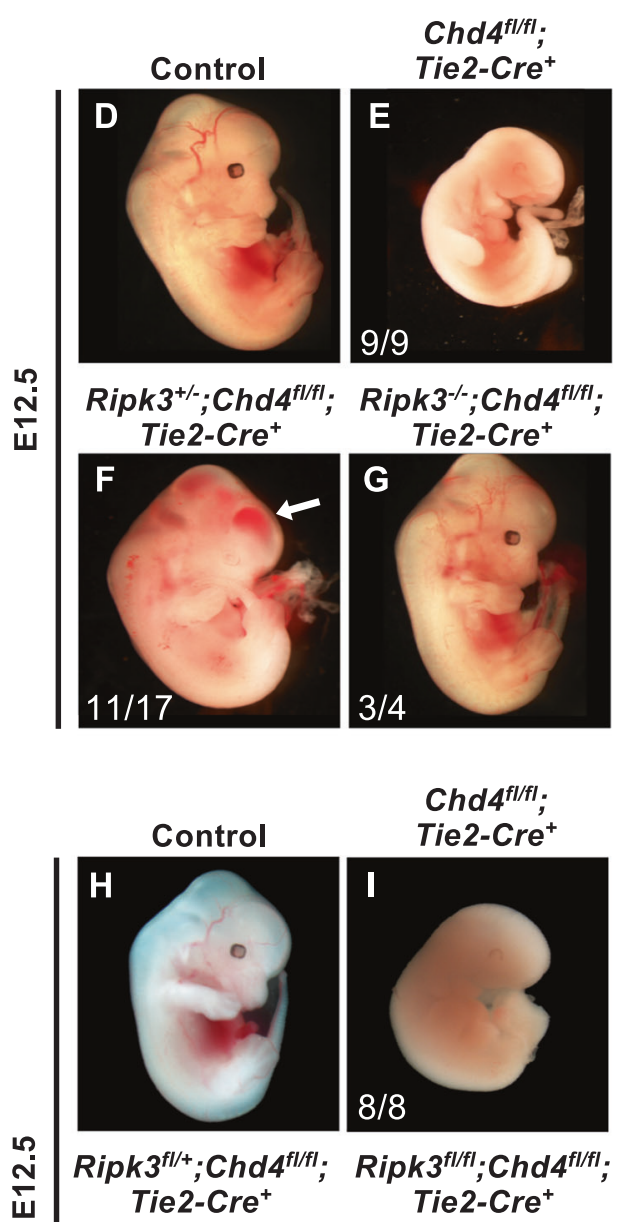

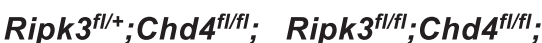

iv Tie2-Cre+
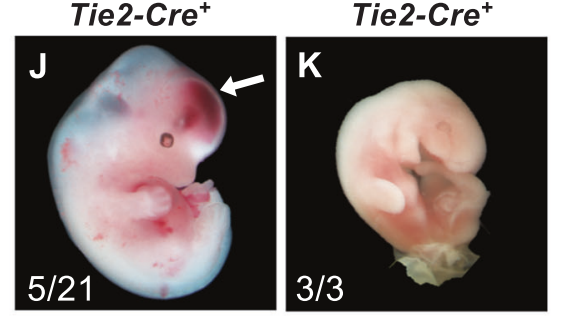

In order to determine whether other necroptosis-related or apoptosis-related genes were misregulated in $C h d 4^{f l f l}$; Tie2-Cre ${ }^{+}$endothelial cells, we examined a panel of transcripts in endothelial cells isolated from E10.5 control versus $\mathrm{Chd} 4^{f / f l}$;Tie2-Cre ${ }^{+}$embryos (Supplementary Fig. S4). We saw upregulation of $M l k l$, which is the downstream target of RIPK3 during necroptosis. However, global Mlkl deletion was not sufficient to rescue $C h d 4^{f l / f} ;$ Tie2-Cre ${ }^{+}$ lethality (Supplementary Fig. S5), which differs from the rescue we saw with Ripk3 deletion (Fig. 2d-k). This indicates that Ripk3 upregulation in $\mathrm{Chd} 4^{f l / f}$;Tie2-Cre ${ }^{+}$endothelial cells may have a detrimental role besides necroptosis. 
Fig. 2 RIPK3 is upregulated in $\mathrm{Chd} 4^{\mathrm{flf} f}$; $\mathrm{Tie} 2-\mathrm{Cr} \mathrm{e}^{+}$embryonic endothelial cells and contributes to vascular rupture. a Endothelial cells were isolated from three sets of E10.5 littermate control and Chd $4^{f l / f}$; Tie2-Cre ${ }^{+}$embryos, RNA was purified, and cDNA was synthesized. Samples were processed for $\mathrm{qPCR}$ analysis of Chd4 and Ripk3 expression. Data are presented as relative fold change over the normalized expression level in cells from control embryos (dotted line). Error bars represent SD. Statistics were calculated using a one-sample $t$ test (one-tailed for Chd4; two-tailed for Ripk3). Asterisk indicates $P<$ 0.05. b, c Cross sections of E10.5 littermate control and Chd4 $4^{\text {fl/fl}}$;Tie2$\mathrm{Cr}^{+}$embryos containing the cardinal vein $(\mathrm{CV})$ were immunostained for the endothelial cell marker PECAM-1 (green) and for RIPK3 (red) and were counterstained with the nucleic acid-binding dye TO-PRO ${ }^{\circ}-3$ (TO-PRO, blue). Images were generated by confocal microscopy. Boxed regions in the top panels are shown magnified in the middle and bottom panels (merged and RIPK3-only channels, respectively). Images are the representative of immunostaining from three separate control and mutant littermate embryos. Scale bars: $50 \mu \mathrm{m}$. d-g Representative images of littermate control (d), Chd $4^{\text {fl/f }} ; \mathrm{Tie}^{-}-\mathrm{Cre}{ }^{+}(\mathbf{e})$,

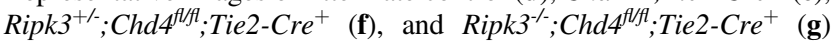
embryos dissected at E12.5. The numbers in the bottom left corner of each image indicate that the picture is representative of $x$ out of $y$ total

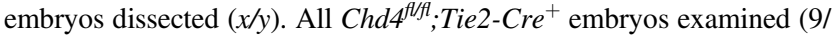
9) were dead and partially resorbed at this timepoint. By contrast 11 out of $17 \mathrm{Ripk}^{+/-} ; \mathrm{Chd}^{\text {fl/fl}}$;Tie2-Cre ${ }^{+}$embryos were comparable in size to littermate control embryos, although they exhibited head bleeding (arrow); the remaining six embryos more closely resembled partially resorbed $\mathrm{Chd4^{f/f }}$; $\mathrm{Tie}^{-} \mathrm{Cr} \mathrm{Cr}^{+}$embryos. Three out of four $\mathrm{Ripk}^{--} ; \mathrm{Chd}^{\mathrm{flfl}} ; \mathrm{Tie2}-\mathrm{Cr} \mathrm{C}^{+}$embryos were indistinguishable from littermate controls. h-k Representative images of littermate control (h),

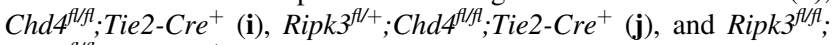
$\mathrm{Chd}^{\mathrm{fllfl}} ; \mathrm{Tie}^{-\mathrm{Cre}^{+}}$(k) embryos dissected at E12.5. Five out of 21

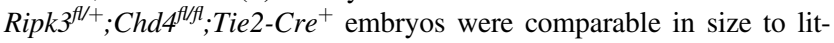
termate control embryos, although they exhibited head bleeding (arrow); the remaining embryos resembled the partially resorbed mutants. Notably, the rescue analyses associated with the Ripk3 global knockout allele $\mathbf{d}-\mathbf{g}$ were performed on a more outbred (CD1) background, and the rescue analyses associated with the Ripk3-flox allele $\mathbf{h}$ $\mathbf{k}$ were performed on a more inbred $(\mathrm{C} 57 \mathrm{~B} 1 / 6 \mathrm{~J})$ background, which we have determined affects the rate of rescue

\section{CHD4 suppresses Ripk3 transcription during hypoxia by preventing acetylation of the Ripk3 promoter region}

We next utilized the commercial murine yolk sac-derived C166 endothelial cell line [22] to determine the mechanism by which CHD4 regulates Ripk3 transcription in endothelial cells. We found CHD4 siRNA knockdown under normal culture conditions to be insufficient to increase Ripk3 transcripts in C166 cells (Fig. 3a). However, since Ripk3

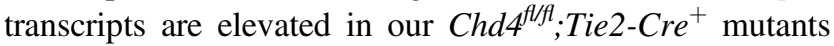
prior to the onset of fetal-placental circulation, when the embryonic environment is particularly hypoxic (Supplementary Fig. S6), we questioned whether hypoxia could influence the regulation of Ripk3 transcription by CHD4. Indeed, when $\mathrm{C} 166$ cells were treated with CHD4 siRNA oligos and then with $\mathrm{CoCl}_{2}$, a hypoxia mimetic [23], Ripk3 transcripts were significantly upregulated (Fig. 3a). To confirm that this upregulation was not due to off-target effects of $\mathrm{CoCl}_{2}$, we also used a hypoxic cell culture chamber to assess Ripk3 transcripts in C166 endothelial cells, and we still saw significant Ripk3 upregulation after CHD4 knockdown in cells grown under $0.5 \% \mathrm{O}_{2}$ (Fig. 3b). A time-course experiment further revealed that Ripk 3 was significantly upregulated at $24 \mathrm{~h}$ after concomitant $\mathrm{CoCl}_{2}$ treatment and CHD4 knockdown (Fig. 3c). Together, these data indicate that CHD4 suppresses Ripk3 transcription in hypoxic endothelial cells.

In order to determine whether Ripk3 is a direct CHD4 target gene, we performed chromatin immunoprecipitation (ChIP) for CHD4 in C166 endothelial cells. We found that CHD4 binds to a conserved region of the Ripk3 promoter located $6.8 \mathrm{~kb}$ upstream $(-6.8 \mathrm{~kb})$ of the transcription start site (TSS) after $\mathrm{CoCl}_{2}$ treatment, but not after vehicle treatment (Fig. 4a, b). Therefore, Ripk3 is indeed a CHD4 target gene under hypoxia-like conditions.

Since CHD4-containing NuRD complexes also contain histone deacetylases 1 and 2 (HDAC1/2) [24], we also used ChIP to assess potential changes in histone acetylation at the Ripk3 promoter upon CHD4 knockdown. We found that histone $\mathrm{H} 3$ acetylation increased at and near the Ripk3 TSS $(0.0$ and $+0.1 \mathrm{~kb})$ after CHD4 knockdown in $\mathrm{CoCl}_{2}$-treated C166 cells (Fig. 4c). These data suggest that CHD4containing NuRD complexes suppress Ripk3 transcription by preventing acetylation and/or actively deacetylating chromatin near the TSS of the gene under hypoxic conditions. Incidentally, we detected no changes in histone $\mathrm{H} 3$ acetylation, $\mathrm{H} 3 \mathrm{~K} 4$ trimethylation (H3K4me3), or DNA methylation in the Ripk3 regulatory regions we analyzed following $\mathrm{CoCl}_{2}$ treatment alone (Supplementary Fig. S7).

\section{HIF and specific-protein-1 (SP1) transcription factors do not promote Ripk3 transcription in $\mathrm{CoCl}_{2}$-treated CHD4-deficient endothelial cells}

Since HIF proteins are stabilized during hypoxia and $\mathrm{CoCl}_{2}$ treatment [25], we sought to determine if HIF transcription factors promote Ripk3 transcription in CHD4-deficient endothelial cells after $\mathrm{CoCl}_{2}$ treatment. Surprisingly, individual knockdown of HIF- $1 \alpha$ or HIF- $2 \alpha$ increased Ripk3 transcripts in $\mathrm{CoCl}_{2}$-treated $\mathrm{C} 166$ cells without additional CHD4 knockdown (Supplementary Fig. S8A). This suggests that these HIFs can repress rather than promote Ripk3 transcription. Furthermore, simultaneous knockdown of CHD4 with either HIF- $1 \alpha$, HIF- $2 \alpha$, or HIF- $1 \alpha / \mathrm{HIF}-2 \alpha$ in $\mathrm{CoCl}_{2}$-treated cells failed to rescue the elevated Ripk3 levels seen in CHD4 knockdown cells (Supplementary Fig. S8A), further suggesting that HIF proteins do not promote Ripk3 transcription in CHD4-deficient endothelial cells under hypoxia-like conditions. 
A qPCR: C166 EC line

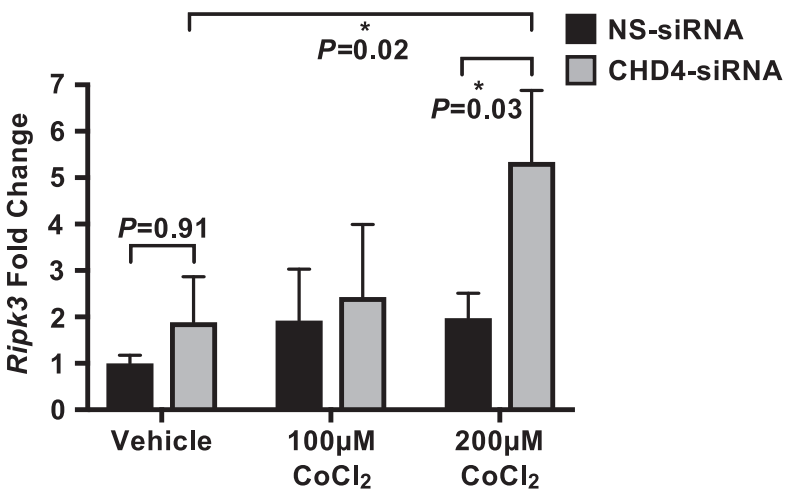

B qPCR: C166 EC line

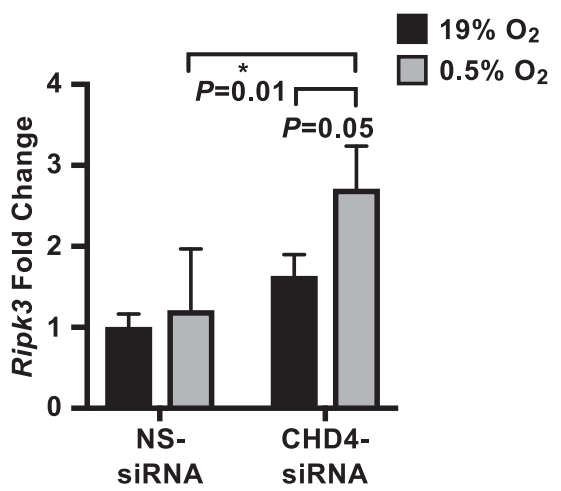

C qPCR: C166 EC line

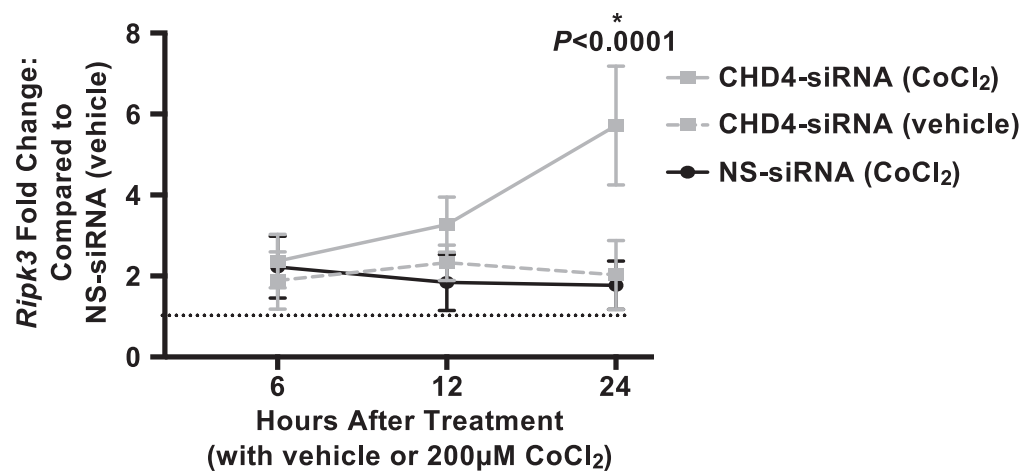

Fig. 3 Ripk3 is upregulated in a cultured embryonic endothelial cell line upon simultaneous CHD4 knockdown and hypoxic conditions. a C166 endothelial cells were transfected with nonspecific (NS) or CHD4-specific siRNA oligos for $24 \mathrm{~h}$ and were subsequently treated with vehicle (water) or $\mathrm{CoCl}_{2}(100$ or $200 \mu \mathrm{M})$ for $24 \mathrm{~h}$. RNA was purified, cDNA was synthesized, and samples were processed for qPCR analysis of Ripk3 expression. Data from three independent experiments were combined and are presented as relative fold change. Error bars represent SD. Statistics were calculated using a two-way ANOVA with Tukey's multiple comparisons test. b C166 endothelial cells were transfected with NS-specific or CHD4-specific siRNA oligos for $24 \mathrm{~h}$ and were subsequently transferred to a hypoxia culture system, where they were cultured under $19 \% \mathrm{O}_{2}$ (normoxia) or $0.5 \%$ $\mathrm{O}_{2}$ (hypoxia) for an additional $24 \mathrm{~h}$. After harvesting at the respective $\mathrm{O}_{2}$ levels, RNA was purified, cDNA was synthesized, and samples

In order to determine whether Ripk3 is a direct HIF target gene in endothelial cells, we performed ChIP for HIF- $1 \alpha$ and found that the transcription factor binds the Ripk3 promoter $(-1.0 \mathrm{~kb})$ in $\mathrm{CoCl}_{2}$-treated $\mathrm{C} 166$ cells (Supplementary Fig. S8B). Therefore, our data indicate that both CHD4 and HIF-1 $\alpha$ repress Ripk 3 transcription and bind to the Ripk3 promoter under hypoxia-like conditions. However, we believe CHD4 is a more critical suppressor of Ripk3 transcription at midgestation than are HIFs, since genetic deletion of HIF-1 $\alpha$ and/or HIF- $2 \alpha$ in endothelial cells is not sufficient to cause bleeding and embryonic lethality $[26,27]$.

We also assessed whether SP1 could be the transcription factor that elevates Ripk3 transcription in endothelial were processed for qPCR analysis of Ripk3 expression. Data from three independent experiments were combined and are presented as relative fold change. Error bars represent SD. Statistics were calculated using a two-way ANOVA with Sidak's multiple comparisons test. c C166 endothelial cells were transfected with NS-specific or CHD4specific siRNA oligos for $24 \mathrm{~h}$ and were subsequently treated with vehicle (water) or $\mathrm{CoCl}_{2}(200 \mu \mathrm{M})$ for up to $24 \mathrm{~h}$. Cells were harvested at 6,12 , or $24 \mathrm{~h}$, RNA was purified, cDNA was synthesized, and samples were processed for qPCR analysis of Ripk3 expression. Data from 3-4 independent experiments were combined and are presented as relative fold change compared to normalized data from NS-siRNA plus vehicle-treated cells (dotted line). Error bars represent SD. Statistics were calculated using a two-way ANOVA with Tukey's multiple comparisons test. For all experiments in this figure, asterisk indicates $P<0.05$

cells after simultaneous CHD4 knockdown and $\mathrm{CoCl}_{2}$ treatment. SP1 is a transcription factor that is upregulated under hypoxia [28, 29] and that directly regulates Ripk3 transcription in cancer cells [30]. Unlike with HIF-1 $\alpha$ and/or HIF-2 $\alpha$ knockdown, SP1 knockdown did not elevate Ripk3 transcripts in $\mathrm{CoCl}_{2}$ treated C166 cells (Supplementary Fig. S8C). Moreover, simultaneous knockdown of CHD4 and SP1 did not rescue the elevated Ripk3 levels seen in $\mathrm{CoCl}_{2}$-treated CHD4 knockdown cells (Supplementary Fig. S8C). Therefore, although we have discovered several proteins that repress Ripk3 transcription (CHD4, HIF- $1 \alpha$, and HIF$2 \alpha$ ), the driver of Ripk 3 transcription during hypoxia is still unknown. 


\section{A Ripk3 promoter conservation across species}

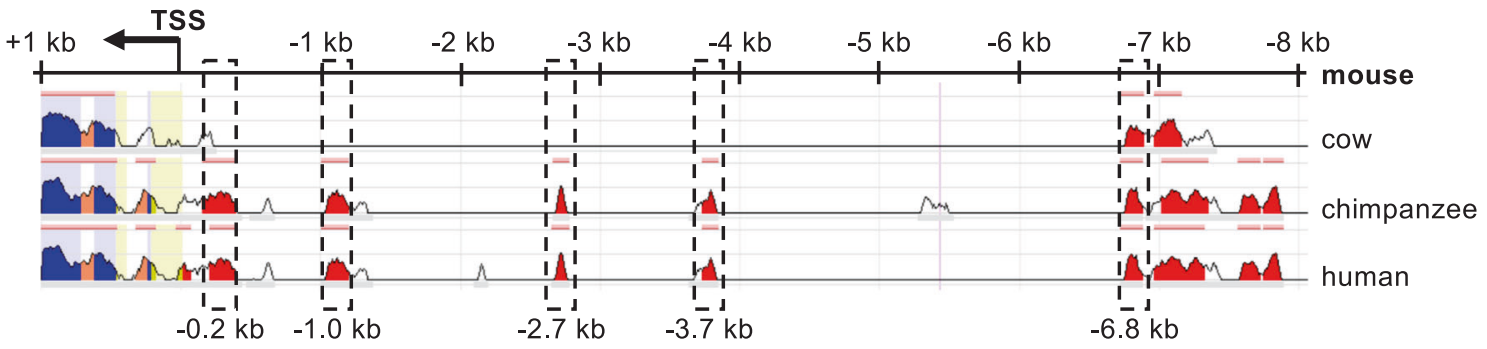

B ChIP: C166 EC line

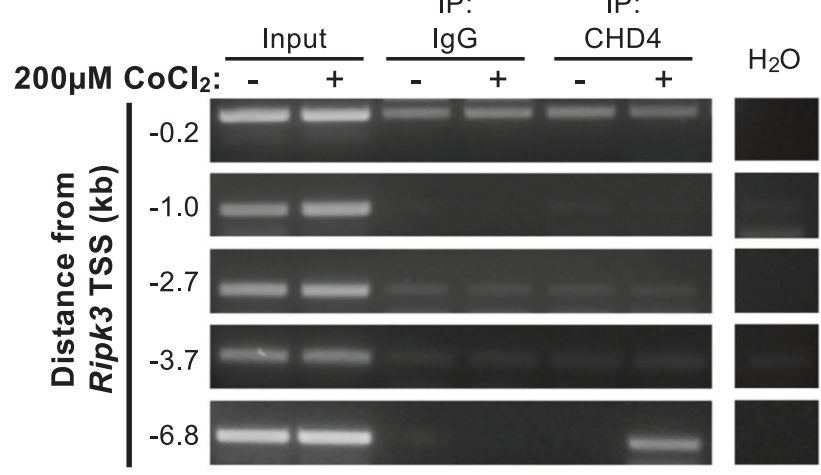

C ChIP: C166 EC line $+200 \mu \mathrm{M} \mathrm{CoCl}{ }_{2}$

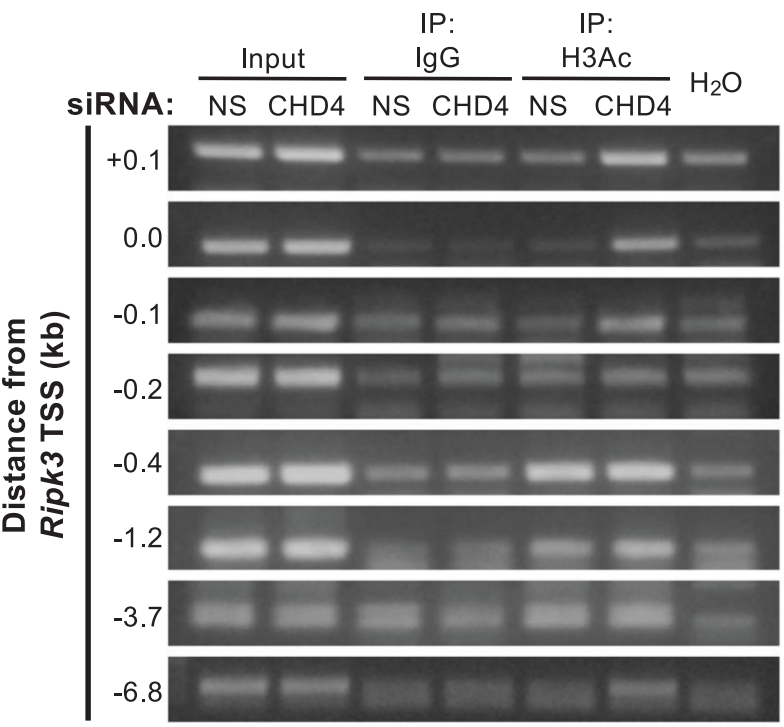

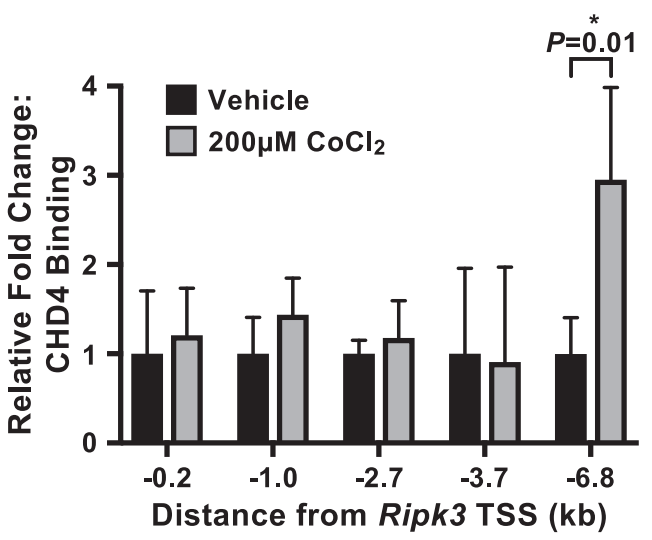

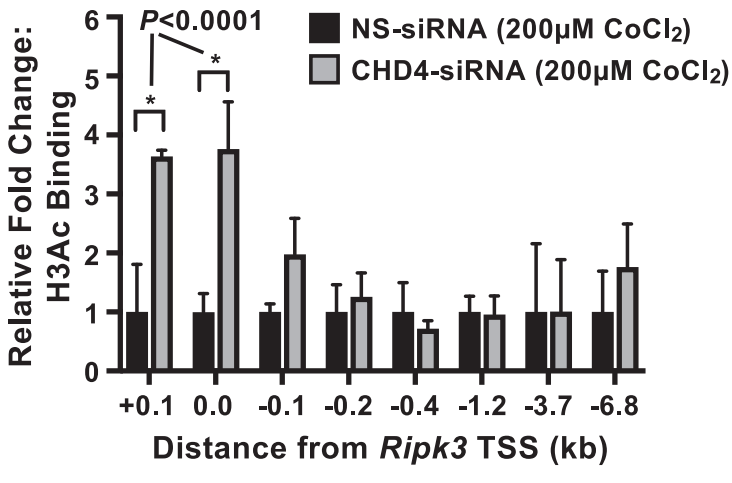

upon our previous evidence that CHD4 also suppresses expression of plasmin-activator genes, which weaken embryonic vasculature by leading to the degradation of extracellular matrix $[4,31]$. Therefore, our data collectively demonstrate that CHD4 tightly regulates multiple transcriptional events during embryonic development to protect vascular integrity.

While RIPK3 overexpression is sufficient to kill cardiomyocytes and aortic smooth muscle cells in culture [32, 33], it is not yet known whether RIPK3 elevation is sufficient to 
4 Fig. 4 CHD4 mediates epigenetic changes at the Ripk3 promoter under hypoxic conditions. a Alignment of the murine Ripk3 promoter region with sequences from cow, chimpanzee, and human genomes from the NCBI DCODE website (http://www.dcode.org). Peak heights indicate degree of sequence homology; pink bars above peaks denote evolutionarily conserved regions; red peaks are found in intragenic regions; yellow shading represents the Ripk3 $5^{\prime}$ untranslated region; blue shading indicates Ripk3 exons. Boxed regions were selected for further analysis by chromatin immunoprecipitation (ChIP) in $\mathbf{b}$ and $\mathbf{c}$; numbers below boxed regions denote approximate distances upstream of the Ripk3 transcription start site (TSS). b ChIP assays were performed in C166 endothelial cells after 24-h treatment with vehicle (water) or with $\mathrm{CoCl}_{2}(200 \mu \mathrm{M})$, using antibodies against CHD4 or against rabbit $\mathrm{IgG}$ (as a negative control). Immunoprecipitated (IP) DNA was isolated and amplified by polymerase chain reaction (PCR) to determine whether CHD4 bound conserved regions in the Ripk3 promoter. Input DNA was isolated from chromatin prior to IP and was used to confirm PCR efficiency. $\mathrm{H}_{2} \mathrm{O}$ was amplified instead of DNA as a negative control for PCR. PCR lanes for each amplicon were run on the same gel but were noncontiguous. In the right panel, PCR band densities from three independent experiments were quantified using ImageJ, normalized to $\mathrm{IgG}$ controls for each experiment, and combined. Data are presented as fold change in CHD4 ChIP levels over the IgG ChIP levels; error bars represent SD. Statistical calculations were performed using a two-way ANOVA with Sidak's multiple comparisons test. c ChIP assays were performed in C166 endothelial cells following 24h knockdown with nonspecific (NS)- or with CHD4-specific siRNA oligos and with a subsequent $24 \mathrm{~h} \mathrm{CoCl}_{2}(200 \mu \mathrm{M})$ treatment period, using antibodies against pan-acetylated histone 3 (H3 Ac) or rabbit IgG (as a negative control). ChIP-PCR was performed as in $\mathbf{b}$ with additional analyses near the Ripk3 TSS at $-0.1,0.0$ (the TSS), and $+0.1 \mathrm{~kb}$. Statistical calculations were performed using a two-way ANOVA with Sidak's multiple comparisons test. For $\mathbf{b}$ and $\mathbf{c}$, asterisk indicates $P<0.05$

trigger endothelial cell death. In our hands, CHD4 knockdown in hypoxia-treated or $\mathrm{CoCl}_{2}$-treated $\mathrm{C} 166$ endothelial cells does not elevate RIPK3 protein levels (Supplementary Fig. S9) or cause cell death (data not shown). This resistance to changes in RIPK3 protein levels and to cell death may be due to the fact that $\mathrm{C} 166$ endothelial cells are transformed [22]. Alternatively, it may indicate that embryonic endothelial cells require an additional unknown trigger to promote RIPK3-mediated death. This concept is supported by our evidence that RIPK3 protein is elevated in endothelial cells

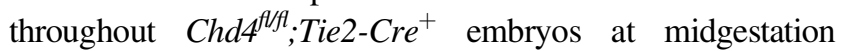
(Fig. 2b, c and Supplementary Fig. S2), although only the large vasculature in the midregion of these embryos is prone to rupture at E11.5 [4]. One possible additional trigger of RIPK3-mediated embryonic endothelial cell death may be the rapid influx of oxygen that occurs into the hypoxic embryonic environment when fetal-placental circulation is established at E10.0. This influx may lead to reactive oxygen species (ROS) generation, cellular damage, cytokine release, and cell death [34], all of which could compromise the integrity of the largest embryonic vessels. We speculate that wild-type embryos evolved protective mechanisms against this rapid oxygenation to prevent cellular damage and vessel rupture. However, when the molecular machinery that controls cell death is imbalanced, as occurs in embryos with insufficient Casp8, Fadd, or Cflar, the rapid oxygenation aberrantly favors RIPK3-mediated death over endothelial cell survival. Likewise, when endothelial RIPK3 is aberrantly upregulated at midgestation in Chd4 mutant embryos, we suspect that there is not enough endogenous apoptotic pathway machinery to prevent RIPK3-mediated necroptosis and vascular rupture. However, future experiments will be needed to determine if excessive RIPK3 and rapid oxygenation are sufficient to trigger embryonic endothelial cell death.

While RIPK3 is an indisputably important mediator of MLKL-mediated necroptosis, recent evidence indicates that it also plays roles outside of necroptosis, including in activation of the NLRP3 inflammasome [35-40]. This concept is supported by the observation that Ripk3 genetic deletion is capable of rescuing some disease models to a greater extent than does $M l k l$ deletion [41]. We believe that the necrotic appearance of the E10.5 Chd4 ${ }^{f l f l}$; Tie2-Cre ${ }^{+}$endothelial cells we observe by electron microscopy suggests that the elevated RIPK3 in those cells does cause necroptosis. However, our failure to rescue vascular rupture in $\mathrm{Chd}^{\mathrm{flfl}}$;Tie2-Cre ${ }^{+}$ embryos with concomitant deletion of Mlkl suggests that excessive RIPK3 may compromise embryonic vascular integrity through mechanisms other than necroptosis. Since RIPK3 can promote inflammation independently of MLKL [39], we immunostained for macrophages in control and Chd $4^{\text {flff }}$;Tie2-Cre ${ }^{+}$embryos at E10.5, one day prior to vascular rupture. Surprisingly, we saw fewer $\mathrm{CD}^{+} 8^{+}$macrophages surrounding major blood vessels in $\mathrm{Chd4^{flfl }}$;Tie2-Cre ${ }^{+}$ mutants versus controls (Supplementary Fig. S10A-C). Furthermore, transcripts for Caspl, interleukin 1 beta $(I l 1 b)$, and tumor necrosis factor alpha (Tnfa) were significantly decreased in $\mathrm{Chd} 4^{\mathrm{flfl}}$; Tie2-Cre ${ }^{+}$mutant endothelial cells at E10.5 (Supplementary Fig. S10D). Therefore excessive RIPK3 correlates with a reduction - rather than an increaseof inflammatory markers in Chd $4^{f l f f}$;Tie2-Cre ${ }^{+}$embryos. We suspect that this reduced inflammation is not a significant contributor to vascular fragility, since $\mathrm{CD}^{+} 8^{+}$macrophages

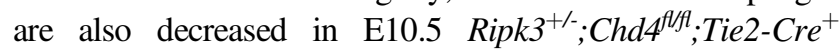
embryos (Supplementary Fig. S10C), which are less prone to vascular rupture than are $\mathrm{Chd4^{f/f }}$;Tie2-Cre ${ }^{+}$embryos at midgestation (Fig. 2f). Finally, there are new reports that RIPK3 can enhance aerobic respiration and ROS generation [42], which may disrupt the preferred metabolic route of glycolysis in endothelial cells at midgestation. Further experiments will be needed to address whether a RIPK3mediated imbalance in endothelial cell metabolism or excessive ROS generation contributes to vascular rupture in $C h d 4^{f l}$ ${ }^{f}$;Tie2-Cre ${ }^{+}$embryos.

An important future goal is to determine if hypoxia and CHD4 continue to regulate endothelial Ripk3 transcription beyond midgestation and past birth. Our lab has reported that CHD4 expression levels decrease dramatically in some 


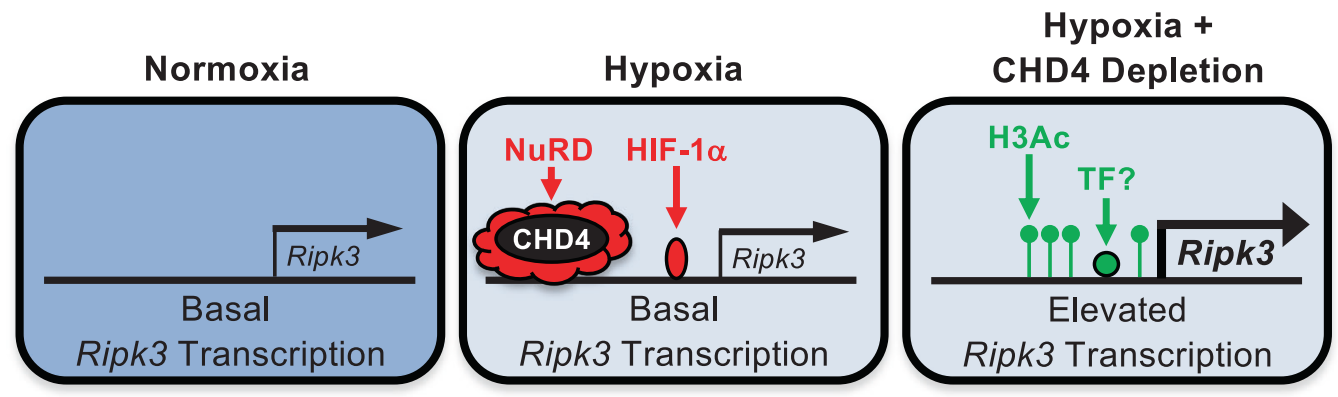

Fig. 5 Model of Ripk 3 transcriptional regulation in embryonic endothelial cells. Our data indicate that embryonic endothelial cells undergo a basal level of Ripk 3 transcription under normoxia conditions and that hypoxia results in the recruitment of transcriptional repressors (CHD4/ NuRD complexes and HIF-1 $\alpha$; red) to the Ripk3 promoter. Upon CHD4 depletion, however, transcriptional activators [H3Ac epigenetic

embryonic tissues between midgestation and birth [31]. Therefore, other suppressors of hypoxia-induced Ripk3 transcription may compensate for CHD4 after midgestation. Hypoxia is an important mediator of ischemic tissue damage, and several mouse models of ischemic diseases are ameliorated on a Ripk3 ${ }^{--}$background [32, 33, 43, 44]. Further investigation will be needed to determine if hypoxia-mediated endothelial Ripk3 transcription contributes to the vascular fragility associated with these pathologies. Likewise, it will be interesting to determine if RIPK3-mediated endothelial cell necroptosis is triggered by ischemia/reperfusion injuries and whether such necroptosis causes collateral damage to surrounding cells through release of damage-associated molecular patterns and other inflammatory mediators. Finally, a recent report that neuronal cells are susceptible to ischemia/reperfusion-mediated necroptosis [45] may indicate that Ripk3 transcription is regulated by oxygen availability in non-endothelial cells as well as endothelial cells. Identifying cells susceptible to hypoxia-mediated Ripk3 transcription and damage could provide new therapeutic strategies for combating a variety of human pathologies associated with ischemia.

\section{Materials and Methods}

\section{Mice}

Chd4-floxed mice (Chd $\left.4^{f / f t}\right)$ [46], Tie2-Cre transgenic mice [14], Ripk $3^{-/-}$mice [47], Cdh5(PAC)-Cre ${ }^{E R T 2}$ transgenic mice [15], Vav-iCre transgenic mice [18], and $M l k l^{--}$mice [48] have been described. Ripk3-floxed mice were generated by Cyagen Biosciences, as described in Supplementary Fig. S3. All mice were maintained on a mixed genetic background at the Oklahoma Medical Research Foundation (OMRF) animal facility. The OMRF Institutional Animal Care and Use Committee approved all animal use protocols. marks and an unknown transcription factor (TF?); green] overlay the promoter and support additional Ripk3 transcription. We find that the excessive endothelial cell Ripk3 transcription that occurs in Chd4 ${ }^{f / f t}$; $\mathrm{Tie}-\mathrm{Cre}^{+}$mutant embryos leads to lethal vascular rupture at midgestation

For induction of the Cdh5(PAC)-Cre $e^{E R T 2}$ transgene, tamoxifen (\#T5648; Sigma) was sonicated in peanut oil (Hain Pure Foods) to a concentration of $20 \mathrm{mg} / \mathrm{mL}$, and $0.1 \mathrm{~mL}$ was administered once daily to pregnant females from E7.5 to 9.5 by oral gavage.

\section{Genotyping}

Tie2-Cre transgenic mice [49], Chd4-floxed mice [50], and $C d h 5(P A C)-C r e^{E R T 2}$ transgenic mice [51] were genotyped as described. Ripk $3^{--}$genotyping was performed by PCR using the following three primers: (5'-AGTCAATCGT TCCTGGATGG-3'), (5'-ACCAGGTGCCCTCCTTACC-3'), and (5'-CTCTTGCTCCCCAGAAGATG-3'). The PCR produced a 213-bp wild-type Ripk3 amplicon and/or a 350-bp Ripk3 knockout amplicon. The Vav-iCre transgene was detected by PCR using a forward primer (5'-AGATGCCAG GACATCAGGAACCTG-3') and a reverse primer (5'-ATCA GCCACACCAGACACAGAGA-3') that yielded a 236-bp amplicon. $M l k l^{--}$genotyping was performed using the following three PCR primers: (5'-TATGACCATGGCAACTC ACG-3'), (5'-ACCATCTCCCCAAACTGTGA-3'), and (5'-T CCTTCCAGCACCTCGTAAT-3'). The PCR produced a 498-bp wild-type $M l k l$ amplicon and/or a 158 Mlkl knockout amplicon. Ripk3-flox mice were genotyped by PCR with a forward primer (5'-CCATCCTCCCTTCATCAAAA-3') and a reverse primer (5'-CGGACTTTGAATGAGCGACT-3') that yielded a 269-bp Ripk3 wild-type amplicon and/or a 339bp Ripk3-flox amplicon.

\section{Semithin light microscopy and TEM}

For semithin microscopy and TEM, tissue samples were fixed by immersion in a mixture of $2 \%$ paraformaldehyde and $2.5 \%$ glutaraldehyde in $0.1 \mathrm{M}$ sodium cacodylate buffer for $1 \mathrm{~h}$, followed by postfixation in $1 \%$ osmium tetroxide (90 $\mathrm{min})$ and $1 \%$ tannic acid $(1 \mathrm{~h})$. Samples were 
subsequently dehydrated in a graded ethanol series and embedded in epoxy resin (EMS). Semithin $(500 \mathrm{~nm})$ and ultrathin sections $(70 \mathrm{~nm})$ were cut using an ultramicrotome (RMC 7000, RMC) equipped with a diamond knife. Semithin sections were stained with epoxy tissue stain (EMS) and analyzed with a Nikon Eclipse E800M microscope equipped with a Nikon DX1200 digital color camera and Nikon ACT-1 image acquisition software. Ultrathin sections were stained with uranyl acetate and lead citrate before being viewed with a Hitachi H-7600 electron microscope equipped with a 4 megapixel digital monochrome camera and AMT-EM image acquisition software (Advanced Microscopy Techniques).

\section{Microarray}

Total RNA was isolated from six control and six $C h d 4^{f l f t}$; Tie2-Cre ${ }^{+}$E9.5 stage-matched embryos using the RNeasy Mini Kit (\#74106; Qiagen). After purification, RNA concentrations were obtained with a scanning spectrophotometer (Nanodrop), and assessed for quality by capillary gel electrophoresis (Agilent 2100 Bioanalyzer, Agilent Technologies). Biotinylated, amplified RNA was produced from $300 \mathrm{ng}$ total RNA per sample and hybridized overnight at $58{ }^{\circ} \mathrm{C}$ to mouse WG-6_v2 Expression BeadChip $^{\mathrm{TM}}$ microarrays (Illumina Corp.). Microarrays were washed under high stringency, labeled with streptavidin$\mathrm{Cy} 3$, and scanned with an Illumina iSCAN scanner. Initial signal intensity values were obtained using the gene expression module (v 1.9.1) in Illumina's Genome Studio software (v.2011-1). Signal intensities were quantile normalized and $\log$ transformed using MatLab software (Mathworks, Inc.). Differential gene expression analyses were performed using BRB-ArrayTools (v 4.2.1, National Cancer Institute, Biometric Research Branch). Genes were filtered using the log expression variation filter to screen out genes that were not likely to be informative based on the variance of each gene across the arrays. Class comparisons between mutant and control samples identified differentially expressed genes using two-sample $t$ tests with a random variance model. Statistical significance was achieved when $P<0.001$. Data were exported to Microsoft Excel, where averages of the classes were used to calculate fold change values.

\section{Endothelial cell isolation}

E10.5 embryos were digested with collagenase-dispaseDNase solution $[1.5 \mathrm{mg} / \mathrm{mL}$ collagenase B (Roche), $1.5 \mathrm{mg} / \mathrm{mL}$ dispase II (Roche), and $25 \mathrm{ug} / \mathrm{mL} \mathrm{rDNaseI}$ (Invitrogen), in sterile 1X Hank's balanced salt solution (Gibco)] at $37^{\circ} \mathrm{C}$ with rocking for $45 \mathrm{~min}$. Dynabeads
(Invitrogen) conjugated to PECAM-1 antibody (\#557355, BD Pharmingen) were added, and samples were incubated for $1 \mathrm{~h}$ at $4{ }^{\circ} \mathrm{C}$ with rotation. Immunoprecipitated cells were washed twice with PBS/0.1\% BSA and eluted in TRIzol (Invitrogen) for RNA analysis.

\section{qPCR}

To analyze transcript levels, total RNA isolated from endothelial cells was purified and treated with RNase-free DNaseI (Qiagen). cDNA was prepared using the iSCRIPT TM Reverse Transcriptase Kit (Bio-Rad), and realtime quantitative PCR was performed using $2 \mathrm{X}$ SYBR green qPCR master mix (Applied Biosystems) and the CFX96 Real-Time System (Bio-Rad) with gene-specific primers. Primers used for qPCR are listed and described in Supplementary Table S1.

\section{qPCR analysis}

The relative fold change in transcription was determined using the comparative CT method and at least two of the four housekeeping genes Gapdh, Rn18s, Rpl13a, and $\beta$-actin as internal controls. Data from at least three independent sets of littermate control and mutant embryos or from at least three independent cell culture experiments were combined and presented as the mean + standard deviation (SD). Statistical differences were calculated in GraphPad Prism 7. Statistical analyses are detailed in the figure legends.

\section{Western blots}

C166 cells were lysed in RIPA buffer with Protease Inhibitor Cocktail (\#P8340; Thermo Fisher Scientific). Cell lysates were centrifuged at $10,000 \mathrm{~g}$ for $15 \mathrm{~min}$ at $4{ }^{\circ} \mathrm{C}$. The supernatant was collected and analyzed. Protein concentration was determined using the Pierce BCA Protein Assay Kit and a NanoDrop 2000 from Thermo Fisher Scientific. Twenty microgram protein was electrophoresed on a 9\% SDS-PAGE gel and then transferred to a PVDF membrane that was blocked in 5\% nonfat dry milk-TBST for $1 \mathrm{~h}$. Primary antibodies (diluted in 5\% milk-TBST) were incubated at $4{ }^{\circ} \mathrm{C}$ overnight with gentle agitation, and membranes were then washed three times ( 15 min each) in TBST. HRP-conjugated secondary antibodies (diluted in $5 \%$ milk-TBST) were applied at room temperature for $1 \mathrm{~h}$ with gentle agitation, and membranes were then washed five times (15 min each) in TBST. Secondary antibodies were detected using ECL Western Blotting Detection Reagent (\# 34076; Thermo Fisher Scientific). Primary antibodies used for immunoblotting: CHD4 (1:1000, \#39289; Active 
Motif), RIPK3 (1:3000, clone 1G6.1.4; Genentech), and GAPDH (1:10,000, \#G9545; Sigma-Aldrich).

\section{Gross embryo imaging}

Gross embryonic images were obtained with a Nikon SMZ800 stereomicroscope and Nikon DS-Fi1 camera and monitor.

\section{Immunofluorescence}

E9.5 and E10.5 Chd $4^{f / f} ;$ Tie2-Cre $^{+}$and littermate control embryos were dissected, fixed in 1\% PFA overnight, and passed through $10 \%$ sucrose for $10 \mathrm{~min}, 15 \%$ sucrose for $30 \mathrm{~min}, 20 \%$ sucrose for $1 \mathrm{~h}$, and a 1:1 mixture of $20 \%$ sucrose and optimal cutting temperature compound (O.C.T.; Sakura Finetek) overnight. Embryos were embedded in O. C.T. the following morning. Yolk sac tissue was used for genotyping. Twelve micrometer sections were cut with a Microm HM 505 E cryotome (Microm International) and adhered to Denville UltraClear microscope slides (Denville Scientific Inc.). Histological sections were permeabilized in $0.1 \%$ Triton X-100 in PBS for 15 min then blocked in blocking solution (3\% BSA) for $2 \mathrm{~h}$ at room temperature. Sections were incubated in primary antibody in $1 \%$ BSA overnight at $4{ }^{\circ} \mathrm{C}$, washed three times quickly in cold $1 \%$ BSA, then incubated for $1 \mathrm{~h}$ at room temperature in secondary antibody in $1 \%$ BSA. Sections intended for viewing on the confocal microscope were then incubated with $1 \mu \mathrm{M}$ TO-PRO ${ }^{\circ}$-3 (\#T3605; Thermo Fisher Scientific) for $10 \mathrm{~min}$ in $3 \%$ BSA. Sections were quickly washed three times with cold 1\% BSA and coverslipped with ProLong Gold (Invitrogen). Confocal images were obtained with a Zeiss LSM710 confocal head mounted on an Axio Observer Z1 stand with Zen 2012 SP2 software (Zeiss). Epifluorescent images were obtained with a Nikon Eclipse Ti-E microscope with NIS-Elements software. Primary antibodies used for immunofluorescence were goat-anti-PECAM-1 (1:100, \#AF3628; R\&D), rat-anti-CD68 (1:250, \#MCA1957; BioRad), and rat-anti-RIPK3 (1:200, clone 1G6.1.4; Genentech). Secondary antibodies used were Cy3-donkeyanti-rat IgG (1:500; Jackson ImmunoResearch) and FITCdonkey-anti-goat IgG (1:500; Jackson ImmunoResearch). For epifluorescent images, Hoechst $(20 \mu \mathrm{g} / \mathrm{mL})$ was added to the secondary antibody incubation.

\section{Hypoxyprobe-1 administration and detection}

Pimonidazole $\mathrm{HCl}$ (Hypoxyprobe-1, \#HP1-100Kit; NPI, Inc.) was dissolved in saline and injected intravenously into pregnant female mice at a concentration of $60 \mathrm{mg} / \mathrm{kg}$. After the probe circulated for $2 \mathrm{~h}$, embryos were dissected and fixed for $24 \mathrm{~h}$ in $1 \%$ PFA, then placed in a 1:1 mixture of
$20 \%$ sucrose and O.C.T overnight. Embryos were embedded in O.C.T. the following morning and cut into $12 \mu \mathrm{m}$ sections. Tissue sections were permeabilized with $0.2 \%$ Tween-20 in PBS for 30 min then blocked for endogenous streptavidin and biotin with the Vector Blocking Kit (\#SP2002; Vector Laboratories, Inc.). Sections were further blocked using the M.O.M. Immunodetection Kit (\#BMK2202; Vector Laboratories, Inc.). Sections were incubated in primary antibody overnight at $4{ }^{\circ} \mathrm{C}$, washed three times quickly in cold $1 \% \mathrm{BSA}$, incubated for $30 \mathrm{~min}$ at room temperature in M.O.M. Biotinylated Anti-Mouse $\operatorname{IgG}$ reagent provided with the M.O.M Immunodetection Kit, and then washed again. Sections were incubated in secondary antibody for $1 \mathrm{~h}$ at room temperature, washed, and coverslipped. Images were obtained with a Nikon Eclipse Ti-E microscope with NIS-Elements software. Primary antibodies used were goat-anti-PECAM-1 (1:100, \#AF3628; R\&D) and mouse-anti-pimonidazole adducts (1:50) as provided with the Hypoxyprobe-1 Kit. Secondary antibodies used were FITC-donkey-anti-goat IgG (1:500; Jackson ImmunoResearch) and Streptavidin-649 (1:100, \#S000-43; Rockland Immunochemicals, Inc.). Hoechst $(20 \mu \mathrm{g} / \mathrm{mL})$ was also added to the secondary antibody incubation.

\section{Cell culture and treatment}

The murine C166 yolk sac-derived endothelial cell line (\#CRL-2581; American Type Culture Collection) was maintained as described [49]. For CHD4, HIF-1 $\alpha$, HIF- $2 \alpha$, and SP1 knockdown, cells were electroporated with $100 \mathrm{nM}$ of CHD4, HIF-1 $\alpha$, HIF-2 $\alpha$, and SP1 Silencer Select or nontargeting control siRNA oligonucleotides (\#s99016, \#s67530, \#s65525, \#s74195, and \#4390844, respectively; Ambion) using Gene Pulser II (BioRad; 250 V, 500uF) in serum-free OptiMEM (Invitrogen). After $24 \mathrm{~h}$, cells were treated with vehicle or the hypoxia mimetic $\mathrm{CoCl}_{2}(200 \mu \mathrm{m})$ for an additional $24 \mathrm{~h}$. For the hypoxia culture chamber system, transfected cells were placed in normoxia $\left(19 \% \mathrm{O}_{2}\right)$ or hypoxia $\left(0.5 \% \mathrm{O}_{2}\right)$ chambers for $24 \mathrm{~h}$. Cells were then harvested at the same respective $\mathrm{O}_{2}$ levels for subsequent transcript analyses.

\section{Chromatin immunoprecipitation}

ChIP was performed as previously described [52]. Specifically, C166 cells $\left(1 \times 10^{6} /\right.$ sample $)$ were fixed on culture dishes with $1 \%$ PFA (10 min) at room temperature. Glycine (125 $\mathrm{mM}$ final) was then added to stop fixation. Cells were scraped, pelleted, and resuspended in $200 \mu \mathrm{l}$ lysis buffer

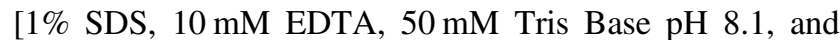
protease inhibitors (\#P8349; Sigma) in water] and incubated on ice $(15 \mathrm{~min}$ ). Lysates were sonicated (four $10 \mathrm{~s}$ pulses at 
an amplitude of 50) using a Misonix S-4000 sonicator. Following sonication, $1.4 \mathrm{ml}$ of dilution buffer $(0.01 \%$ SDS, $1.1 \%$ Triton X-100, $1.2 \mathrm{mM}$ EDTA, $16.7 \mathrm{mM}$ Tris Base $\mathrm{pH}$ $8.1,166.5 \mathrm{mM} \mathrm{NaCl}$, and protease inhibitors in water) was added to each sample. Samples were then precleared using protein A/G-conjugated agarose beads (Calbiochem) for $3 \mathrm{~h}$ at $4{ }^{\circ} \mathrm{C}$ with rotation. Agarose beads were pelleted, and $5 \mu \mathrm{g}$ of anti-CHD4 [a cocktail of (\#ab70469; Abcam) plus (\#39289; Active Motif)], anti-HIF-1 $\alpha$ (a cocktail of \#ab179483 plus \#ab2185; Abcam), anti-H3Ac (\#06-599; Millipore), anti-H3K4Me3 (\#39959; Active Motif), or rabbit IgG (\#NI01-100UG; Lot 3050723; Millipore) antibodies were added to supernatants and rotated overnight at $4{ }^{\circ} \mathrm{C}$. Samples were next incubated with $60 \mu$ of protein $\mathrm{A} / \mathrm{G}$ agarose beads for $3 \mathrm{~h}$ at $4^{\circ} \mathrm{C}$ with rotation. Antigen complexes were pelleted by centrifugation and washed (two times each) with $750 \mu \mathrm{l}$ of low salt buffer $(0.1 \%$ SDS, $1 \%$ Triton X-100, 2 mM EDTA, $40 \mathrm{mM}$ Tris $\mathrm{HCl} \mathrm{pH}$ 8.1, and $150 \mathrm{mM} \mathrm{NaCl}$ ), LiCl buffer (1 mM EDTA, $250 \mathrm{mM} \mathrm{LiCl}$, and $1 \% \mathrm{Na}$ Deoxycholate), and TE buffer (1 mM EDTA, and $5 \mathrm{mM}$ Tris $\mathrm{pH} \mathrm{7.4)}$ and rotated at $4^{\circ} \mathrm{C}$ for $5 \mathrm{~min}$. Antigen was eluted by incubating with $500 \mu \mathrm{l}$ of elution buffer $(1 \% \mathrm{SDS}$ and $100 \mathrm{mM} \mathrm{NaHCO}$ ) under rotation at room temperature for $30 \mathrm{~min}$. Crosslinks were reversed by incubating samples in $200 \mathrm{mM} \mathrm{NaCl}$ at $65^{\circ} \mathrm{C}$ overnight. DNA was purified by Proteinase K treatment $(20 \mathrm{mg} / \mathrm{mL})$, phenol-chloroform extraction, and ethanol precipitation. DNA was resuspended in $25 \mu \mathrm{l}$ of TE and PCR amplified. Primers used for ChIP-PCR are listed in Supplementary Table S2. Amplicon density was determined from three independent experiments using ImageJ software (NIH). Band density of the immunoprecipitated samples was normalized to that of the input samples and divided by the $\operatorname{IgG}$ negative control bands.

\section{DNA methylation Assay}

Cytosine methylation in the promoter region of Ripk 3 was determined by bisulfite amplicon sequencing as previously described [52]. Genomic DNA was isolated from C166 cells. Purified genomes were modified with bisulfate and harvested using the EZ-96 DNA Methylation Mag Prep Kit (\#D5040; Zymo) according to the manufacturer's instructions. The modified Ripk3 promoter region near the TSS was amplified with the following primers: $5^{\prime}$ TGGGTTTTTTTTTTTATAGAAAAGAA-3' and $3^{\prime}$ CAACTTCCCTTTCAAATAAAAAAC- ${ }^{\prime}$. PCR products were cleaned of primers, enzymes, and dNTPs using the Illustra GFX PCR DNA Purification Kit (GE Healthcare). Dual-indexed sequencing libraries were generated using Nextera XT library preparation, sized by capillary electrophoresis. Sequencing was performed using the Illumina MiSeq benchtop sequencer as previously described [53].
FASTQ files were mapped, aligned, and analyzed with MethylSeq against genomic regions of the Ripk3 locus of mm10/GRCm38.

Acknowledgements We thank K. Georgopoulos for Chd4-floxed mice, V. Dixit for Ripk $3^{-/}$mice, W. Alexander for $M l k l^{--}$mice, R. Adams for $C d h 5(P A C)-C r e^{E R T 2}$ mice, Genentech for anti-RIPK3 antibody, B. Frank and the OMRF Microarray Core for technical assistance with microarrays, T. Griffin for help with and use of his hypoxic culture chamber system, W. Freeman and the OUHSC Targeted DNA Methylation \& Mitochondrial Heteroplasmy Core for help with bisulfite sequencing, and Griffin lab members for helpful discussions.

Funding This study was supported in part by NIH grants HL111178, HL134778, HL144605, and GM103441 awarded to CTG and GM114731 awarded to CTG and FL, by grants from the Oklahoma Center for the Advancement of Science and Technology (HR11-013 and HR15-078) awarded to CTG, by grants from the American Heart Association (15GRNT25090015) awarded to CTG, (16POST31300013) awarded to MM, and (19PRE343800708) awarded to SG, and by a grant from the Presbyterian Health Foundation awarded to CTG.

\section{Compliance with ethical standards}

Conflict of interest The authors declare that they have no conflict of interest.

Publisher's note: Springer Nature remains neutral with regard to jurisdictional claims in published maps and institutional affiliations.

\section{References}

1. Dunwoodie SL. The Role of hypoxia in development of the mammalian embryo. Dev Cell. 2009;17:755-73.

2. Tsai Y-P, Wu K-J. Epigenetic regulation of hypoxia-responsive gene expression: Focusing on chromatin and DNA modifications. Int J Cancer. 2014;134:249-56.

3. Batie M, Del Peso L, Rocha S. Hypoxia and chromatin: a focus on transcriptional repression mechanisms. Biomedicines. 2018;6:47.

4. Ingram KG, Curtis CD, Silasi-Mansat R, Lupu F, Griffin CT. The NuRD chromatin-remodeling enzyme CHD4 promotes embryonic vascular integrity by transcriptionally regulating extracellular matrix proteolysis. PLoS Genet. 2013;9:e1004031.

5. Linask KK, Han M, Bravo-Valenzuela NJM. Changes in vitelline and utero-placental hemodynamics: implications for cardiovascular development. Front Physiol. 2014;5:390.

6. Dillon CP, Tummers B, Baran K, Green DR. Developmental checkpoints guarded by regulated necrosis. Cell Mol Life Sci. 2016;73:2125-36.

7. Newton K. RIPK1 and RIPK3: critical regulators of inflammation and cell death. Trends Cell Biol. 2015;25:347-53.

8. Vandenabeele P, Galluzzi L, Vanden Berghe T, Kroemer G. Molecular mechanisms of necroptosis: an ordered cellular explosion. Nat Rev Mol Cell Biol. 2010;11:700-14.

9. Varfolomeev EE, Schuchmann M, Luria V, Chiannilkulchai N, Beckmann JS, Mett IL, et al. Targeted disruption of the mouse Caspase 8 gene ablates cell death induction by the TNF receptors, Fas/Apo1, and DR3 and is lethal prenatally. Immunity. 1998;9:267-76.

10. Yeh WC, Itie A, Elia AJ, Ng M, Shu HB, Wakeham A, et al. Requirement for Casper (c-FLIP) in regulation of death receptor- 
induced apoptosis and embryonic development. Immunity. 2000;12:633-42.

11. Yeh WC, Pompa JL, McCurrach ME, Shu HB, Elia AJ, Shahinian A, et al. FADD: essential for embryo development and signaling from some, but not all, inducers of apoptosis. Science. 1998;279:1954-8.

12. Kaiser WJ, Upton JW, Long AB, Livingston-Rosanoff D, DaleyBauer LP, Hakem R, et al. RIP3 mediates the embryonic lethality of caspase-8-deficient mice. Nature. 2011;471:368-72.

13. Dillon CP, Oberst A, Weinlich R, Janke LJ, Kang TB, Ben-Moshe T, et al. Survival function of the FADD-CASPASE-8-cFLIP(L) complex. Cell Rep. 2012;1:401-7.

14. Kisanuki YY, Hammer RE, Miyazaki J, Williams SC, Richardson JA, Yanagisawa M. Tie2-Cre transgenic mice: a new model for endothelial cell-lineage analysis in vivo. Dev Biol. 2001;230:230-42.

15. Wang Y, Nakayama M, Pitulescu ME, Schmidt TS, Bochenek ML, Sakakibara A, et al. Ephrin-B2 controls VEGF-induced angiogenesis and lymphangiogenesis. Nature. 2010;465:483-6.

16. Joseph C, Quach JM, Walkley CR, Lane SW, Lo Celso C, Purton LE. Deciphering hematopoietic stem cells in their niches: a critical appraisal of genetic models, lineage tracing, and imaging strategies. Cell Stem Cell. 2013;13:520-33.

17. Monvoisin A, Alva JA, Hofmann JJ, Zovein AC, Lane TF, IruelaArispe ML. VE-cadherin-CreERT2 transgenic mouse: a model for inducible recombination in the endothelium. Dev Dyn. 2006;235:3413-22.

18. de Boer J, Williams A, Skavdis G, Harker N, Coles M, Tolaini M, et al. Transgenic mice with hematopoietic and lymphoid specific expression of Cre. Eur J Immunol. 2003;33:314-25.

19. He C, Hu H, Braren R, Fong S-Y, Trumpp A, Carlson TR, et al. cmyc in the hematopoietic lineage is crucial for its angiogenic function in the mouse embryo. Development. 2008;135:2467-77.

20. Siegemund S, Shepherd J, Xiao C, Sauer K. hCD2-iCre and VaviCre mediated gene recombination patterns in murine hematopoietic cells. PLoS ONE. 2015;10:e0124661.

21. Vanden Berghe T, Grootjans S, Goossens V, Dondelinger Y, Krysko DV, Takahashi N, et al. Determination of apoptotic and necrotic cell death in vitro and in vivo. Methods. 2013;61:117-29.

22. Wang SJ, Greer P, Auerbach R. Isolation and propagation of yolksac-derived endothelial cells from a hypervascular transgenic mouse expressing a gain-of-function fps/fes proto-oncogene. Vitr Cell Dev Biol Anim. 1996;32:292-9.

23. Ho VT, Bunn HF. Effects of transition metals on the expression of the erythropoietin gene: further evidence that the oxygen sensor is a heme protein. Biochem Biophys Res Commun. 1996;223:175-80.

24. Zhang Y, Ng HH, Erdjument-Bromage H, Tempst P, Bird A, Reinberg D. Analysis of the NuRD subunits reveals a histone deacetylase core complex and a connection with DNA methylation. Genes Dev. 1999;13:1924-35.

25. Yuan Y, Hilliard G, Ferguson T, Millhorn DE. Cobalt inhibits the interaction between hypoxia-inducible factor-alpha and von Hippel-Lindau protein by direct binding to hypoxia-inducible factor-alpha. J Biol Chem. 2003;278:15911-6.

26. Wei H, Bedja D, Koitabashi N, Xing D, Chen J, Fox-Talbot K, et al. Endothelial expression of hypoxia-inducible factor 1 protects the murine heart and aorta from pressure overload by suppression of TGF-beta signaling. Proc Natl Acad Sci USA. 2012;109: E841-850.

27. Skuli N, Liu L, Runge A, Wang T, Yuan L, Patel S, et al. Endothelial deletion of hypoxia-inducible factor-2alpha (HIF2alpha) alters vascular function and tumor angiogenesis. Blood. 2009;114:469-77.
28. Jeong JK, Park SY. Transcriptional regulation of specific protein 1 (SP1) by hypoxia-inducible factor 1 alpha (HIF-1alpha) leads to PRNP expression and neuroprotection from toxic prion peptide. Biochem Biophys Res Commun. 2012;429:93-8.

29. Koizume S, Miyagi Y. Diverse mechanisms of Sp1-dependent transcriptional regulation potentially involved in the adaptive response of cancer cells to oxygen-deficient conditions. Cancers. 2015;8:2.

30. Yang C, Li J, Yu L, Zhang Z, Xu F, Jiang L, et al. Regulation of RIP3 by the transcription factor $\mathrm{Sp} 1$ and the epigenetic regulator UHRF1 modulates cancer cell necroptosis. Cell Death Dis. 2017;8:e3084.

31. Crosswhite PL, Podsiadlowska JJ, Curtis CD, Gao S, Xia L, Srinivasan RS, et al. CHD4-regulated plasmin activation impacts lymphovenous hemostasis and hepatic vascular integrity. J Clin Investig. 2016;126:2254-66.

32. Luedde M, Lutz M, Carter N, Sosna J, Jacoby C, Vucur M, et al. RIP3, a kinase promoting necroptotic cell death, mediates adverse remodelling after myocardial infarction. Cardiovasc Res. 2014;103:206-16.

33. Wang Q, Liu Z, Ren J, Morgan S, Assa C, Liu B. Receptorinteracting protein kinase 3 contributes to abdominal aortic aneurysms via smooth muscle cell necrosis and inflammation. Circ Res. 2015;116:600-11.

34. Kalogeris T, Baines CP, Krenz M, Korthuis RJ. Cell biology of ischemia/reperfusion injury. Int Rev Cell Mol Biol. 2012;298:229-317.

35. Moriwaki K, Balaji S, McQuade T, Malhotra N, Kang J, Chan FK. The necroptosis adaptor RIPK3 promotes injury-induced cytokine expression and tissue repair. Immunity. 2014;41:567-78.

36. Moriwaki K, Bertin J, Gough PJ, Chan FK. A RIPK3-caspase 8 complex mediates atypical pro-IL-1beta processing. J Immunol. 2015;194:1938-44.

37. He S, Wang X. RIP kinases as modulators of inflammation and immunity. Nat Immunol. 2018;19:912-22.

38. Mandal P, Berger SB, Pillay S, Moriwaki K, Huang C, Guo H, et al. RIP3 induces apoptosis independent of pronecrotic kinase activity. Mol Cell. 2014;56:481-95.

39. Lawlor KE, Khan N, Mildenhall A, Gerlic M, Croker BA, D’Cruz AA, et al. RIPK3 promotes cell death and NLRP3 inflammasome activation in the absence of MLKL. Nat Commun. 2015;6:6282.

40. Wong WW, Vince JE, Lalaoui N, Lawlor KE, Chau D, Bankovacki A, et al. cIAPs and XIAP regulate myelopoiesis through cytokine production in an RIPK1- and RIPK3-dependent manner. Blood. 2014;123:2562-72.

41. Newton K, Dugger DL, Maltzman A, Greve JM, Hedehus M, Martin-McNulty B, et al. RIPK3 deficiency or catalytically inactive RIPK1 provides greater benefit than MLKL deficiency in mouse models of inflammation and tissue injury. Cell Death Differ. 2016;23:1565-76.

42. Qiu X, Zhang Y, Han J. RIP3 is an upregulator of aerobic metabolism and the enhanced respiration by necrosomal RIP3 feeds back on necrosome to promote necroptosis. Cell Death Differ. 2018;25:821-4.

43. Lin J, Li H, Yang M, Ren J, Huang Z, Han F, et al. A role of RIP3-mediated macrophage necrosis in atherosclerosis development. Cell Rep. 2013;3:200-10.

44. Chen H, Fang Y, Wu J, Chen H, Zou Z, Zhang X, et al. RIPK3MLKL-mediated necroinflammation contributes to AKI progression to CKD. Cell Death Dis. 2018;9:878.

45. Yang J, Zhao Y, Zhang L, Fan H, Qi C, Zhang K, et al. RIPK3/ MLKL-mediated neuronal necroptosis modulates the M1/M2 polarization of microglia/macrophages in the ischemic cortex. Cereb Cortex. 2018;28:2622-35. 
46. Williams CJ, Naito T, Arco PG, Seavitt JR, Cashman SM, De Souza $\mathrm{B}$, et al. The chromatin remodeler Mi-2beta is required for CD4 expression and T cell development. Immunity. 2004;20:719-33.

47. Newton K, Sun X, Dixit VM. Kinase RIP3 is dispensable for normal NF-kappa Bs, signaling by the B-cell and T-cell receptors, tumor necrosis factor receptor 1 , and Toll-like receptors 2 and 4. Mol Cell Biol. 2004;24:1464-9.

48. Murphy JM, Czabotar PE, Hildebrand JM, Lucet IS, Zhang JG, Alvarez-Diaz S, et al. The pseudokinase MLKL mediates necroptosis via a molecular switch mechanism. Immunity. 2013;39:443-53.

49. Griffin CT, Curtis CD, Davis RB, Muthukumar V, Magnuson T. The chromatin-remodeling enzyme BRG1 modulates vascular Wnt signaling at two levels. Proc Natl Acad Sci USA. 2011;108:2282-7.
50. Curtis CD, Griffin CT. The chromatin-remodeling enzymes BRG1 and CHD4 antagonistically regulate vascular Wnt signaling. Mol Cell Biol. 2012;32:1312-20.

51. Wiley MM, Muthukumar V, Griffin TM, Griffin CT. SWI/ SNF chromatin-remodeling enzymes Brahma-related gene 1 (BRG1) and Brahma (BRM) are dispensable in multiple models of postnatal angiogenesis but are required for vascular integrity in infant mice. J Am Heart Assoc. 2015;4: e001972.

52. Menendez MT, Griffin CT. Characterizing epigenetic changes in endothelial cells. Methods Mol Biol. 2018;1846:335-44.

53. Masser DR, Stanford DR, Freeman WM. Targeted DNA methylation analysis by next-generation sequencing. J Vis Exp. 2015. https://doi.org/10.3791/52488. 